\title{
The effect of atmospheric pressure on oxygen saturation and dyspnea: the Tromsø study
}

\author{
Lisa M. E. Dohmen ${ }^{1} \cdot$ Mark Spigt $^{1,2}$ (1) $\cdot$ Hasse Melbye ${ }^{2}$ \\ Received: 27 November 2018 / Revised: 17 February 2020 / Accepted: 19 February 2020 / Published online: 3 March 2020 \\ (C) The Author(s) 2020
}

\begin{abstract}
A drop in atmospheric pressure, as observed at high altitudes, leads to decreased oxygen saturation. The effect of regular changes in barometric pressure at sea level has never been studied in a general population. A cohort of adults aged 40 years were examined with pulse oximetry at two separate visits, and the local barometric pressure was available from the local weather station. The study aimed at determining the effect of atmospheric pressure on oxygen saturation also called $\mathrm{SpO}_{2}$, as well as on shortness of breath. Based on spirometry, the participants were divided into two groups, with normal and decreased lung function. Decreased lung function was defined as forced expiratory volume in $1 \mathrm{~s}\left(\mathrm{FEV}_{1}\right)$ below lower limit or normal (LLN) or FEV /FVC $_{\text {(FVC, }}$ forced vital capacity) below LLN, with GLI 2012 reference values. The statistical analysis included uni/multivariable linear and logistic regression. A total of 7439 participants of the Troms $\varnothing 7$ cohort study were included. There was a significant association between barometric pressure and $\mathrm{SpO}_{2}<96 \%$, and we found that a reduction of $166.67 \mathrm{hPa}$ was needed to get a $1 \%$ reduction in $\mathrm{SpO}_{2}$. The change in atmospheric pressure was not significantly associated with shortness of breath, also not in subjects with reduced lung function.
\end{abstract}

Keywords Atmospheric pressure $\cdot$ Oxygen saturation $\cdot$ Dyspnea $\cdot$ Sea level $\cdot$ Daily pressure changes

\section{Introduction}

The respiratory system is influenced by weather conditions (Celenza et al. 1996; D'Amato et al. 2013; Ferrari et al. 2012; Michelozzi et al. 2007; Qiu et al. 2013; Spence et al. 1993; Tseng et al. 2013). In a study of 25 million ambulatory visits by COPD patients, temperature, wind speed, air pressure at sea level, and humidity had a significant influence in 1-2\% of the ambulatory visits (Ferrari et al. 2012).

The weather is for a large part determined by barometric pressure (Barry and Chorley 2009). When the atmospheric pressure is decreased, the oxygen saturation is decreased as well (Horiuchi et al. 2018). Even moderate altitude has been found to be associated with a small decrease in oxygen saturation. Goldberg et al. found a mean oxygen saturation of

Mark Spigt

m.spigt@maastrichtuniversity.nl

1 Department of Family Medicine, CAPHRI, Maastricht University, P.O. Box 616, 6200 MD Maastricht, The Netherlands

2 General Practice Research Unit, Department of Community Medicine, UiT The Arctic University of Norway, Tromsø, Norway
$98.1 \%$ in a population of healthy young adults at $750 \mathrm{~m}$ altitude, compared to $98.5 \%$ in a comparable population at $43 \mathrm{~m}$ altitude (Goldberg et al. 2012).

A study with recreational climbers indicated significant changes in pulse oximetry, peak flow, and heart rate when reaching a height of about $1000 \mathrm{~m}$ (Napoli et al. 2009). However, no shortness of breath, also called dyspnea, could be observed during a state of hypobaric hypoxia at rest in healthy individuals (Nakano et al. 2015).

The aim of our study was to determine the influence of daily atmospheric pressure changes on oxygen saturation and shortness of breath in a general population at sea level.

\section{Materials and methods}

\section{Population}

Participants of the 7th survey of the Tromsø study were included. Tromsø 7 took place between March 2015 and October 2016 in Tromsø, a city at sea level in the northern part of Norway. All inhabitants in Tromsø aged 40 years or more were invited to the survey and $65 \%$ attended. A total of 
21,083 participants were thus included. After a random selection procedure, with increased coverage of those age 60 years or more, 9324 participants were invited to a second visit with extended examinations. Included in this study were those with valid pulse oximetry at both visits measured on days with barometric pressure data available (Fig. 1). The Regional Committee for Medical and Health Research Ethics in North Norway approved Tromsø 7 survey. All participants gave written informed consent.

\section{Questionnaires}

The participants answered questions on self-reported diseases such as chronic respiratory and cardiovascular diseases, smoking habit, chronic cough, and shortness of breath, using the modified Medical Research Council (mMRC) questionnaire. At visit 2, there was a computerized questionnaire at the spirometry station, with questions on symptoms of airway infection the previous week and on change in shortness of breath-How is your breathing today compared to normal: less short of breath, as normal, or more short of breath.

\section{Measurements}

The atmospheric pressure was measured, at Tromsø Airport, Langnes, in $\mathrm{hPa}$ for every day during the Tromsø study by the Norwegian Meteorological Institute, and values corresponding to dates of visit 1 or 2 were used. The oxygen saturation was measured with a digital handheld pulse oximeter (Onyx II, model 9559; Nonin Medical, Inc.; Plymouth, MN, USA) at visit 1 and 2 . The participant had to rest $15 \mathrm{~min}$ before the examination. The best of three measurements was used. Decreased oxygen saturation was defined as $\mathrm{SpO}_{2} \leq 95 \%$ (Vold et al. 2012), and values below $80 \%$ were regarded as invalid. To determine the lung function of the participants, spirometry was performed using SensorMedics Vmax 20c Encore system (Viasys Healthcare Respiratory Technologies, Yorba Linda, CA, USA). The American Thoracic Society/ European Respiratory Society criteria were followed (Miller et al. 2005). Calibration was performed every morning. Three trained technicians conducted the spirometry alternately. The participants were sitting and used a nose clip during the measurement. At least three exhalations were required. The difference between the best and second-best FEV1 was used and FVC was not to exceed $5 \%$ or $150 \mathrm{~mL}$. Current drug therapy was not interrupted before the test. Reference values from GLI 2012 were used (Langhammer et al. 2016).

\section{Statistical analysis}

Patient characteristics were compared by using independent ttest and Chi-square test for trend. Participants with and without decreased lung function, defined as FEV1/FVC $<$ LLN or FEV1 < LLN, were compared. The barometric pressures were divided into quartiles, and oxygen saturation was dichotomized into normal and decreased values $\left(\mathrm{SpO}_{2}<96 \%\right)$. A linear regression was performed to determine the association between the change in atmospheric pressure between visit 1 and visit 2 and the corresponding change in oxygen saturation. The association between change in atmospheric pressure between visit 1 and visit 2 and increased shortness of breath at visit 2 (as outcome) was analysed with logistic regression.
Fig. 1 Flowchart indicating selection of study participants

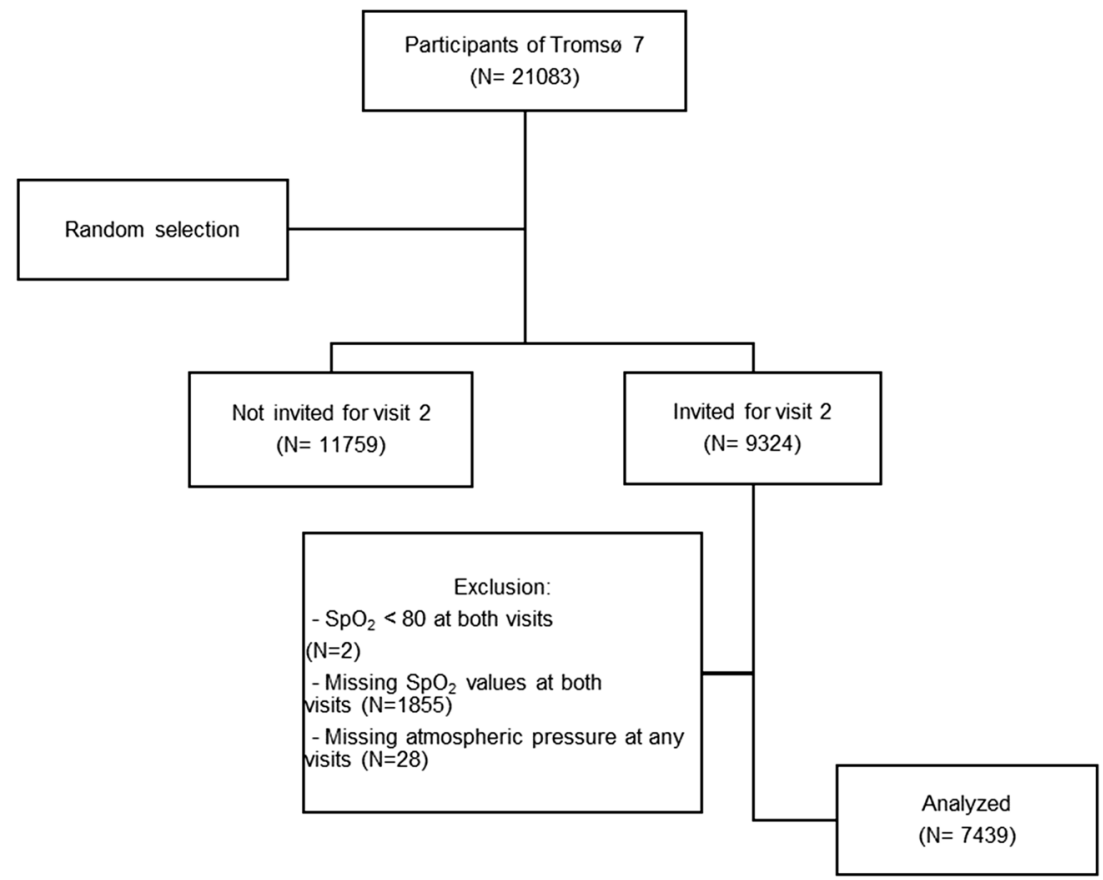


Multivariate models were applied with possible confounders added to atmospheric pressure: self-reported heart attack, COPD, asthma, current smoking, symptoms of airway infection the week before visit 2, chronic shortness of breath (mMRC $\geq 2$ ), and significantly reduced lung function as measured by spirometry. Also age and sex were included in the models. In all analyses, IBM SPSS version 24 was used and a $p$ value below 0.05 was considered statistically significant.

\section{Results}

Among the 7439 participants included, 4065 were women $(54.6 \%)$ and 3374 were men (45.4\%). The mean number of days between the first and the second visit was 50 (SD 34.8). According to spirometry, 995 subjects had reduced lung function. The percentages with self-reported diseases such as asthma, COPD, and smoking were higher in participants with reduced lung function (Table 1).

\section{Atmospheric pressure}

The atmospheric pressure ranged from $958 \mathrm{hPa}$ to $1039 \mathrm{hPa}$ (Fig. 2). The mean was 1007.3 at first visit and 1007.9 at second visit.

\section{Prevalence of decreased oxygen saturation $\left(\mathrm{SpO}_{2}<\right.$ 96\%)}

The prevalence of $\mathrm{SpO}_{2}<96 \%$ was $5.0 \%$, and significantly higher in those with reduced lung function, $11.1 \%$ than in those with normal lung function, 3.8\% $(p<0.001)$ (data not

Table 1 Participant characteristics

\begin{tabular}{|c|c|c|c|c|}
\hline & Total $N=7439$ & $\begin{array}{l}\text { Reduced lung function } \\
N=995\end{array}$ & $\begin{array}{l}\text { No reduced lung function } \\
N=6271\end{array}$ & $p$ value \\
\hline Age (mean) & $63.22(40-84)$ & $63.73(40-84)$ & $63.02(40-84)$ & $0.048^{\mathrm{a}}$ \\
\hline Sex & & & & $0.505^{\mathrm{b}}$ \\
\hline Women & $4065(54.6 \%)$ & $532(13.4 \%)$ & $3424(86.6 \%)$ & \\
\hline Men & $3374(45.4 \%)$ & $463(14.0 \%)$ & 2847 (86.0\%) & \\
\hline \multicolumn{5}{|l|}{$\mathrm{SpO}_{2}$ (mean) } \\
\hline Visit 1 & $97.8(87-100)$ & $97.33(87-100)$ & $97.89(89-100)$ & $<0.001 \mathrm{a}$ \\
\hline Visit 2 & $97.62(84-100)$ & $97.22(89-100)$ & $97.69(90-100)$ & $<0.001 \mathrm{a}$ \\
\hline Increased dyspnea at visit 2 & & & & $<0.001^{\mathrm{b}}$ \\
\hline Yes & $847(11.4 \%)$ & $185(22.9 \%)$ & $624(77.1 \%)$ & \\
\hline No & $6592(88.6 \%)$ & $810(12.5 \%)$ & $5647(87.5 \%)$ & \\
\hline Smoking & & & & $<0.001^{\mathrm{c}}$ \\
\hline Yes & $901(12.1 \%)$ & $258(29.4 \%)$ & $619(70.6 \%)$ & \\
\hline Previously & $3603(48.4 \%)$ & $522(14.9 \%)$ & $2988(85.1 \%)$ & \\
\hline Never & $2857(38.4 \%)$ & $208(7.4 \%)$ & $2596(92.6 \%)$ & \\
\hline $\mathrm{mMRC} \geq 2$ & & & & $<0.001^{\mathrm{b}}$ \\
\hline Yes & $376(5.1 \%)$ & $121(35.0 \%)$ & $225(65.0 \%)$ & \\
\hline No & $7047(94.7 \%)$ & $873(12.6 \%)$ & $6031(87.4 \%)$ & \\
\hline \multicolumn{5}{|l|}{ Self-reported disease: } \\
\hline Asthma & & & & $<0.001^{\mathrm{b}}$ \\
\hline Yes & $823(11.1 \%)$ & $241(30.4 \%)$ & $551(69.6 \%)$ & \\
\hline No & $6353(85.4 \%)$ & $710(11.4 \%)$ & $5506(88.6 \%)$ & \\
\hline COPD & & & & $<0.001^{\mathrm{b}}$ \\
\hline Yes & $313(4.2 \%)$ & $167(56.6 \%)$ & $128(43.4 \%)$ & \\
\hline No & $6817(91.6 \%)$ & $770(11.5 \%)$ & $5901(88.5 \%)$ & \\
\hline Symptoms of airway infection the previous 7 days at visit 2 : & & & & $<0.001^{\mathrm{b}}$ \\
\hline Yes & $1077(14.5 \%)$ & $182(17.4 \%)$ & $865(82.6 \%)$ & \\
\hline No & $6340(85.2 \%)$ & $809(13.1 \%)$ & $5388(86.9 \%)$ & \\
\hline Heart attack & & & & $0.003^{\mathrm{b}}$ \\
\hline Yes & $365(4.9 \%)$ & $67(18.9 \%)$ & $287(81.1 \%)$ & \\
\hline No & 6788 (91.2\%) & $885(13.3 \%)$ & $5747(86.7 \%)$ & \\
\hline
\end{tabular}

$p$ values according to ${ }^{\mathrm{a}}$ independent $\mathrm{t}$-test, ${ }^{\mathrm{b}} \mathrm{\chi}^{2}$ and ${ }^{\mathrm{c}} \mathrm{\chi}^{2}$ for trend, as indicated 
Fig. 2 Barometric pressure day by day during Tromsø 7. Missing values are due to a break of the study in the months of July
1060

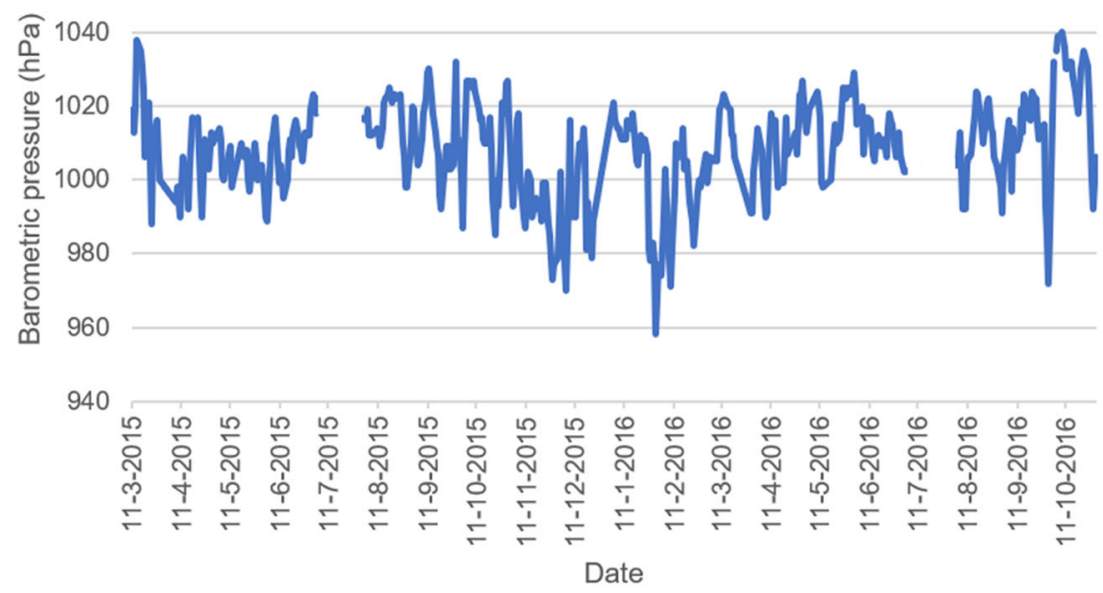

shown in table). The prevalence decreased with increasing quartile of barometric pressure. This is shown in Fig. 3 for visit 2, where this association was statistically significant for both participants with normal lung and reduced lung function, $p=0.002$ and $p=0.005$, respectively. Similar results were found at visit 1 , but with nonsignificant association in the group with reduced lung function.

\section{Increased shortness of breath}

Among all participants, $11.4 \%$ reported to be more short of breath than usual at visit 2 . There was a tendency of decreasing frequency of increased dyspnea with increasing barometric pressure (Fig. 3), but the association was not statistically significant, neither among participants with normal lung function $(p=0.2)$ nor among those with reduced lung function $(p=0.1)$.

\section{Change in oxygen saturation}

The $\mathrm{SpO}_{2}$ value was unchanged between visit 1 and visit 2 in 2845 participants $(38.2 \%), 1 \%$ increase or decrease was found in $42.1 \%$, a $2 \%$ change in $14.8 \%$, and a change of $3 \%$ or more in $4.8 \%$. Linear regression showed a significant association between the change in barometric pressure and change in $\mathrm{SpO}_{2}$ with $\beta=0.006$ ( $\left.p<0.001 ; 95 \% \mathrm{CI}=0.004-0.008\right)$. This means that a reduction of $1 \mathrm{hPa}$ in barometric pressure results in a reduction of 0.006 in oxygen saturation (Fig. 4), and that a reduction of $166.7 \mathrm{hPa}$ was needed to get a $1 \%$ reduction in $\mathrm{SpO}_{2}$.
Fig. 3 Association between barometric pressure $(\mathrm{hPa}$, quartiles) and the frequency of $\mathrm{SpO}_{2}<96 \%$ and increased shortness of breath at visit 2 in participants with normal and reduced lung function. Chi-square test for trend has been applied

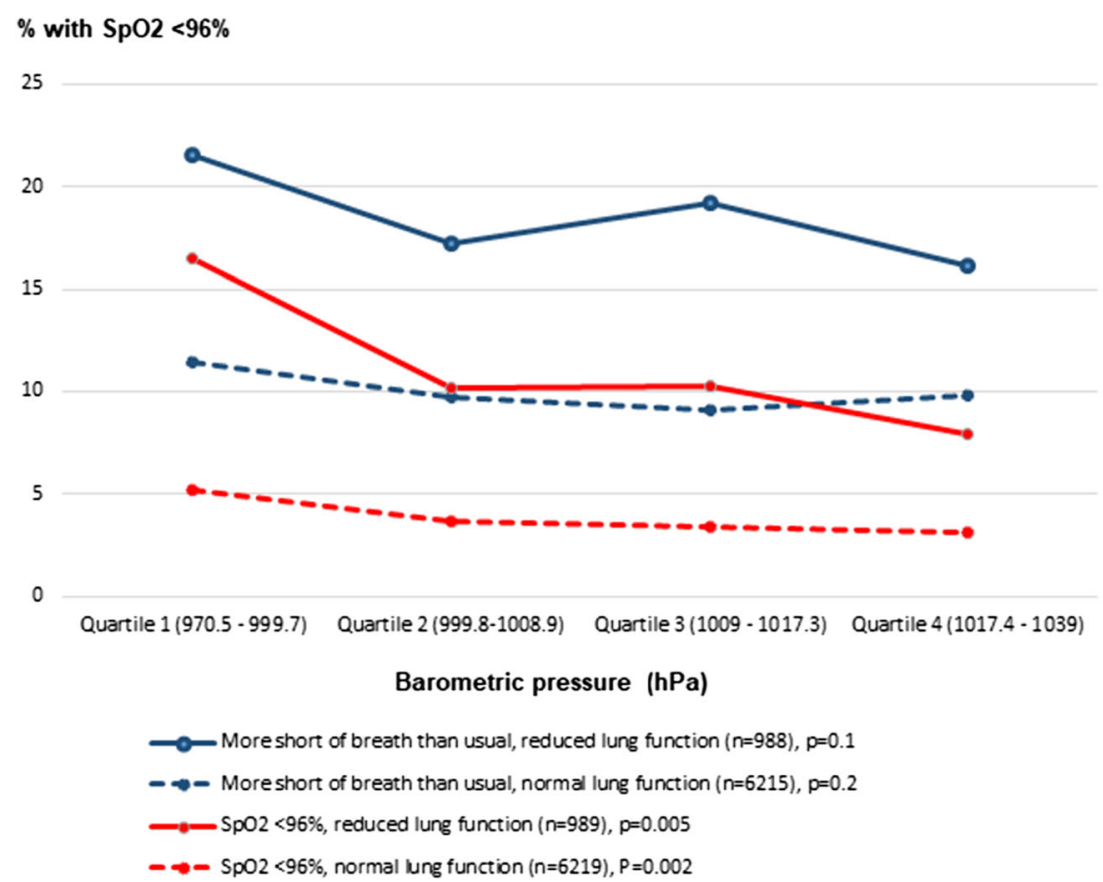


Fig. 4 The association between change in barometric pressure $(\mathrm{hPa})$ and change in $\mathrm{SpO} 2(\%)$ between visit 1 and $2, \beta=0.006$

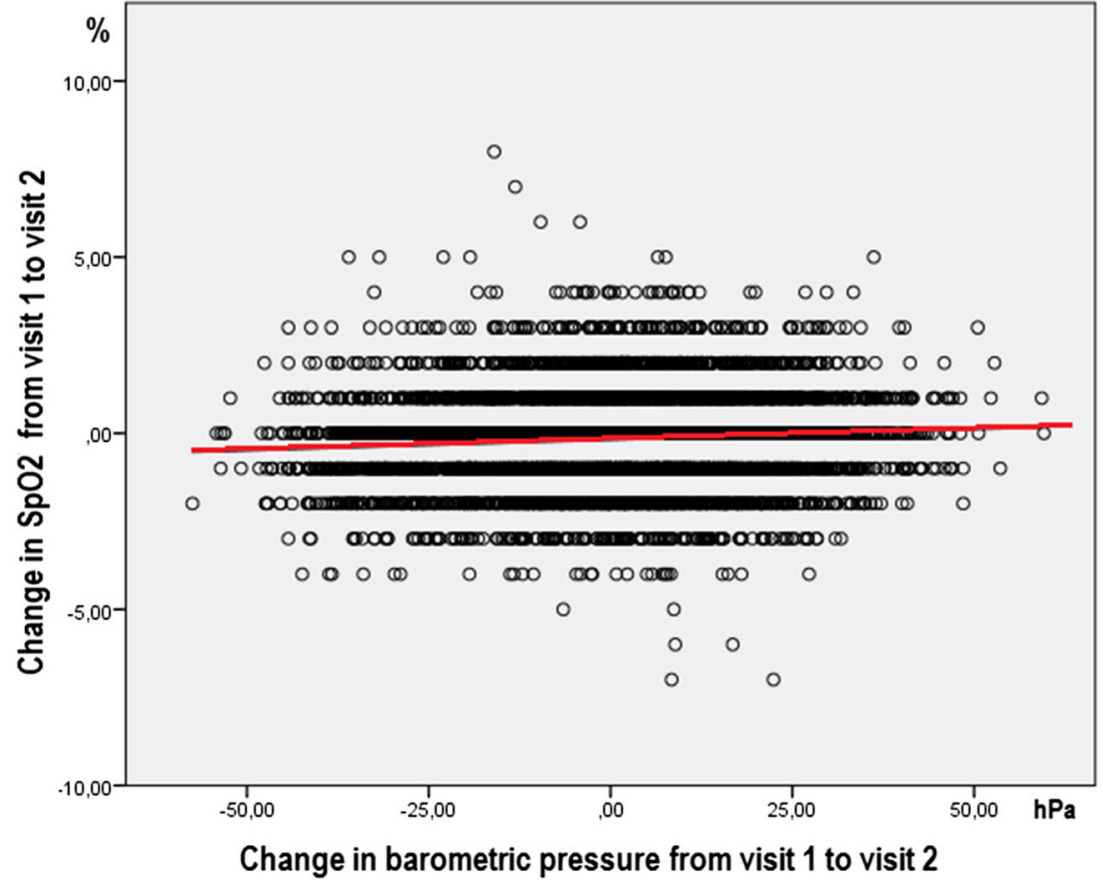

Table 2 Multivariable analysis for change in $\mathrm{SpO}_{2}$

\begin{tabular}{|c|c|c|c|c|}
\hline & $\beta$ unadjusted $(95 \% \mathrm{CI})$ & $p$ value & $\beta$ adjusted $(95 \% \mathrm{CI})$ & $p$ value \\
\hline Change atmospheric pressure & $0.006(0.004-0.008)$ & $<0.001$ & $0.006(0.005-0.008)$ & $<0.001$ \\
\hline Age & $0.002(0.000-0.005)$ & 0.1 & $0.002(0.000-0.005)$ & 0.09 \\
\hline \multicolumn{5}{|l|}{ Sex } \\
\hline Woman & Reference & & & \\
\hline Men & $-0.022(-0.078-0.035)$ & 0.4 & $-0.012(-0.071-0.047)$ & 0.7 \\
\hline \multicolumn{5}{|l|}{ Smoking } \\
\hline No currently & Reference & & & \\
\hline Yes & $0.083(-0.003-0.169)$ & 0.06 & $0.067(-0.024-0.158)$ & 0.2 \\
\hline \multicolumn{5}{|l|}{ Asthma } \\
\hline No & Reference & & & \\
\hline Yes & $0.049(-0.040-0.139)$ & 0.3 & $0.026(-0.072-0.124)$ & 0.6 \\
\hline \multicolumn{5}{|l|}{ COPD } \\
\hline No & Reference & & & \\
\hline Yes & $0.125(-0.015-0.264)$ & 0.08 & $-0.002(-0.126-0.158)$ & 1.0 \\
\hline \multicolumn{5}{|l|}{ Heart attack } \\
\hline No & Reference & & & \\
\hline Yes & $0.017(-0.113-0.147)$ & 0.8 & $0.014(-0.125-0.153)$ & 0.8 \\
\hline \multicolumn{5}{|l|}{$\mathrm{mMRC} \geq 2$} \\
\hline No & Reference & & & \\
\hline Yes & $0.211(0.083-0.339)$ & 0.001 & $0.183(0.039-0.327)$ & 0.01 \\
\hline \multicolumn{5}{|l|}{ Reduced lung function } \\
\hline No & Reference & & & \\
\hline Yes & $0.084(0.001-0.166)$ & 0.05 & $0.049(-0.042-0.140)$ & 0.3 \\
\hline \multicolumn{5}{|l|}{ Airway infection visit 2} \\
\hline No & Reference & & & \\
\hline Yes & $-0.013(-0.093-0.067)$ & 0.7 & $-0.030(-0.114-0.054)$ & 0.5 \\
\hline
\end{tabular}


Table 3 Multivariable analysis for increased dyspnea

\begin{tabular}{|c|c|c|c|c|}
\hline & OR $(95 \% \mathrm{CI})$ & $p$ value & OR adjusted $(95 \% \mathrm{CI})$ & $p$ value \\
\hline Change atmospheric pressure & $1.000(0.996-1.005)$ & 0.862 & $1.001(0.996-1.005)$ & 0.7 \\
\hline Age & $0.990(0.983-0.997)$ & 0.004 & $0.988(0.980-0.996)$ & 0.002 \\
\hline \multicolumn{5}{|l|}{ Sex } \\
\hline Woman & Reference & & & \\
\hline Men & $1.054(0.913-1.217)$ & 0.5 & $1.083(0.917-1.279)$ & 0.3 \\
\hline \multicolumn{5}{|l|}{ Smoking currently } \\
\hline No & Reference & & & \\
\hline Yes & $2.306(1.924-2.763)$ & $<0.001$ & $1.887(1.525-2.334)$ & $<0.001$ \\
\hline \multicolumn{5}{|l|}{ Asthma } \\
\hline No & Reference & & & \\
\hline Yes & $1.964(1.618-2.384)$ & $<0.001$ & $1.526(1.198-1.944)$ & 0.001 \\
\hline \multicolumn{5}{|l|}{ COPD } \\
\hline No & Reference & & & \\
\hline Yes & $2.271(1.715-3.007)$ & $<0.001$ & $1.248(0.874-1.782)$ & 0.2 \\
\hline \multicolumn{5}{|l|}{ Heart attack } \\
\hline No & Reference & & & \\
\hline Yes & $1.019(0.733-1.418)$ & 0.9 & $0.859(0.578-1.275)$ & 0.5 \\
\hline \multicolumn{5}{|l|}{$\mathrm{mMRC} \geq 2$} \\
\hline No & Reference & & & \\
\hline Yes & $3.819(3.027-4.818)$ & $<0.001$ & $3.643(2.713-4.890)$ & $<0.001$ \\
\hline \multicolumn{5}{|l|}{ Reduced lung function } \\
\hline No & Reference & & & \\
\hline Yes & $2.067(1.727-2.474)$ & $<0.001$ & $0.118(1.022-1.604)$ & 0.03 \\
\hline \multicolumn{5}{|l|}{ Airway infection visit 2} \\
\hline No & Reference & & & \\
\hline Yes & $6.860(5.865-8.024)$ & $<0.001$ & $6.858(5.777-8.141)$ & $<0.001$ \\
\hline
\end{tabular}

For participants with reduced lung function, the association was also significant $\beta=0.007(p=0.006 ; 95 \% \mathrm{CI}=0.002-$ 0.012).

When adjusted for possible confounders in multivariable analysis, change in atmospheric pressure remained a significant predictor of change in $\mathrm{SpO}_{2}$ (Table 2).

\section{Increased shortness of breath and change in barometric pressure}

In the multivariable logistic regression with increased shortness of breath at visit 2 as outcome, change in barometric pressure was not a significant predictor. The strongest predictors were recent airway infection, $\mathrm{mMRC}$, and smoking currently. Age, asthma, and reduced lung function were also significant predictors (Table 3 ).

\section{Discussion}

Atmospheric pressure at sea level was significantly associated with oxygen saturation. This was the case in participants with reduced lung function as well as in those with normal lung function, as measured by spirometry. A reduction in atmospheric pressure was not associated with increased dyspnea.

To get a $1 \%$ reduction in $\mathrm{SpO}_{2}$, a drop in barometric pressure of $166.67 \mathrm{hPa}$ was needed. A similar drop can be attained when climbing from sea level to an altitude of $1400 \mathrm{~m}$, as, normally, barometric pressure decreases by about $12 \mathrm{hPa}$ per $100 \mathrm{~m}$ in the first $1000 \mathrm{~m}$, using the formula for pressure and height (NASA 1976; Quick 2004). Our results correspond to the difference in oxygen saturation of $0.42 \%$ when measurements at $725 \mathrm{~m}$ and $43 \mathrm{~m}$ were compared (Goldberg et al. 2012). Greater effect of change in altitude has been found in individuals ascending to higher altitudes. One study of 19 healthy adults showed $\mathrm{SpO}_{2}$ values at $2305 \mathrm{~m}$ of $93.8 \%$ dropping to $90.2 \%$ at $3000 \mathrm{~m}$ (Horiuchi et al. 2018). In another study, ascending towards an altitude of $2100 \mathrm{~m}$ (from $490 \mathrm{~m}$ to $2590 \mathrm{~m}$ ) led to a decrease of $4 \%$ in $\mathrm{SpO}_{2}$, measured in healthy men in the evening (Stadelmann et al. 2015). The barometric pressure dropped from $959 \mathrm{hPa}$ (719 Torr) to $749 \mathrm{hPa}$ (562 Torr) which means that a change of $52,5 \mathrm{hPa}$ was needed for a change of $1 \%$ in $\mathrm{SpO}_{2}$. The starting point before change in altitude may play a role, and at the same 
natural changes in barometric pressure might have a greater impact on oxygen saturation at high altitude than at sea level. A particularly large drop in oxygen saturation has been found in COPD patients, from a mean of $96 \%$ at sea level to $87 \%$ at $2438 \mathrm{~m}$, with further decrease during exercise (Christensen et al. 2000).

The change in barometric pressure in our study was not associated with shortness of breath, also not in participants with decreased lung function. This has previously been found in healthy adults (Nakano et al. 2015). There are considerable effects of altitude in patients with cardiac or respiratory disease. Asthma patients can develop moderate loss of asthma control, increased airway obstruction and neutrophilic airway inflammation (Seys et al. 2013). Development of severe hypoxia was described by Christensen and co-workers (Christensen et al. 2000), but the association with increased dyspnea was not studied. We still do not know whether shortness of breath can be induced at high altitude in patients with cardiac or respiratory diseases.

\section{Strengths and limitations}

The large study population is an important strength, also the routine collection of barometric pressures carried out independent of the Tromsø study. There are some limitations. A limitation is that not all kinds of weather circumstances were included, only the atmospheric pressure. It is known from studies that temperature, humidity, etc. have an influence on respiratory symptoms (Celenza et al. 1996; D'Amato et al. 2013; Ferrari et al. 2012; Michelozzi et al. 2007; Qiu et al. 2013; Spence et al. 1993; Tseng et al. 2013). Questionnaires were used to collect information on shortness of breath and possible confounders, like smoking and self-reported diseases, which means that recall bias could be a problem. Another limitation was the attendance rate of Tromsø 7. Although higher than in most population surveys, under representation of those too sick to attend could lead to bias. It is also a limitation that, concerning external validity, the sample consisted only of Norwegians. The close to polar climate in Tromsø may have affected the influence of other weather characteristics than the barometric pressure.

\section{Conclusion}

Atmospheric pressure was strongly associated with oxygen saturation at sea level, but the association was weaker than previously found at high altitudes. Change in atmospheric pressure was not a predictor for reporting increased dyspnea, also not in subjects with reduced lung function. More research is needed to determine the effect of atmospheric pressure on increased dyspnea.
Acknowledgements Thanks to participants and staff of the 7th Tromsø Study. Also thanks to the Norwegian Meteorological Institute for access to the barometric data.

\section{Compliance with ethical standards}

The authors declare that they have no conflict of interest.

Open Access This article is licensed under a Creative Commons Attribution 4.0 International License, which permits use, sharing, adaptation, distribution and reproduction in any medium or format, as long as you give appropriate credit to the original author(s) and the source, provide a link to the Creative Commons licence, and indicate if changes were made. The images or other third party material in this article are included in the article's Creative Commons licence, unless indicated otherwise in a credit line to the material. If material is not included in the article's Creative Commons licence and your intended use is not permitted by statutory regulation or exceeds the permitted use, you will need to obtain permission directly from the copyright holder. To view a copy of this licence, visit http://creativecommons.org/licenses/by/4.0/.

\section{References}

Barry RG, Chorley RJ (2009) Atmosphere, weather and climate. Routledge, London. https://doi.org/10.4324/9780203871027

Celenza A, Fothergill J, Kupek E, Shaw RJ (1996) Thunderstorm associated asthma: a detailed analysis of environmental factors. BMJ 312:604-607. https://doi.org/10.1136/bmj.312.7031.604

Christensen C, Ryg M, Refvem O, Skjonsberg O (2000) Development of severe hypoxaemia in chronic obstructive pulmonary disease patients at 2,438 m (8,000 ft) altitude. Eur Respir J 15:635-639. https://doi.org/10.1183/09031936.05.00093104

D'Amato G et al (2013) Climate change, air pollution and extreme events leading to increasing prevalence of allergic respiratory diseases. Multidiscip Respir Med 8:12. https://doi.org/10.1186/2049-6958$8-12$

Ferrari U, Exner T, Wanka ER, Bergemann C, Meyer-Arnek J, Hildenbrand B, Tufman A, Heumann C, Huber RM, Bittner M, Fischer R (2012) Influence of air pressure, humidity, solar radiation, temperature, and wind speed on ambulatory visits due to chronic obstructive pulmonary disease in Bavaria, Germany. Int $\mathbf{J}$ Biometeorol 56:137-143. https://doi.org/10.1007/s00484-0110405-x

Goldberg S, Buhbut E, Mimouni FB, Joseph L, Picard E (2012) Effect of moderate elevation above sea level on blood oxygen saturation in healthy young adults. Respiration 84:207-211. https://doi.org/10. $1159 / 000336554$

Horiuchi M, Endo J, Handa Y, Nose H (2018) Barometric pressure change and heart rate response during sleeping at $3000 \mathrm{~m}$ altitude. Int J Biometeorol 62:909-912. https://doi.org/10.1007/s00484-017$1487-\mathrm{x}$

Langhammer A, Johannessen A, Holmen TL, Melbye H, Stanojevic S, Lund MB, Melsom MN, Bakke P, Quanjer PH (2016) Global lung function initiative 2012 reference equations for spirometry in the Norwegian population. Eur Respir J 48(6):1602-1611. https://doi. org/10.1183/13993003.00443-2016

Michelozzi P, Kirchmayer U, Katsouyanni K, Biggeri A, McGregor G, Menne B, Kassomenos P, Anderson HR, Baccini M, Accetta G, Analytis A, Kosatsky T (2007) Assessment and prevention of acute health effects of weather conditions in Europe, the PHEWE project: background, objectives, design. Environ Health 6:12. https://doi. org/10.1186/1476-069X-6-12 
Miller MR, Hankinson J, Brusasco V, Burgos F, Casaburi R, Coates A, Crapo R, Enright P, van der Grinten C, Gustafsson P, Jensen R, Johnson DC, MacIntyre N, McKay R, Navajas D, Pedersen OF, Pellegrino R, Viegi G, Wanger J, ATS/ERS Task Force (2005) Standardisation of spirometry. Eur Respir J 26:319-338. https:// doi.org/10.1183/09031936.05.00034805

Nakano T, Iwazaki M, Sasao G, Nagai A, Ebihara A, Iwamoto T, Kuwahira I (2015) Hypobaric hypoxia is not a direct dyspnogenic factor in healthy individuals at rest. Respir Physiol Neurobiol 218: 28-31. https://doi.org/10.1016/j.resp.2015.07.009

Napoli AM, Milzman DP, Damergis JA, Machan J (2009) Physiologic affects of altitude on recreational climbers. Am J Emerg Med 27: 1081-1084. https://doi.org/10.1016/j.ajem.2008.09.025

NASA (1976) U.S. standard atmosphere 1976. US government printing office, Washington, DC

Qiu H, Yu ITS, Wang X, Tian L, Tse LA, Wong TW (2013) Season and humidity dependence of the effects of air pollution on COPD hospitalizations in Hong Kong. Atmos Environ 76:74-80. https://doi. org/10.1016/j.atmosenv.2012.07.026

Quick A (2004) Derivation relating altitude to air pressure. Portland State, Aerospace Society

Seys SF, Daenen M, Dilissen E, Van Thienen R, Bullens DM, Hespel P, Dupont LJ (2013) Effects of high altitude and cold air exposure on airway inflammation in patients with asthma. Thorax 68:906-913. https://doi.org/10.1136/thoraxjnl-2013-203280

Spence DP, Graham DR, Ahmed J, Rees K, Pearson MG, Calverley PM (1993) Does cold air affect exercise capacity and dyspnea in stable chronic obstructive pulmonary disease? Chest 103:693-696. https:// doi.org/10.1378/chest.103.3.693

Stadelmann K, Latshang TD, Lo Cascio CM, Clark RA, Huber R, Kohler M, Achermann P, Bloch KE (2015) Impaired postural control in healthy men at moderate altitude $(1630 \mathrm{~m}$ and $2590 \mathrm{~m})$ : data from a randomized trial. PLoS One 10:e0116695. https://doi.org/10.1371/ journal.pone. 0116695

Tseng C-M, Chen YT, Ou SM, Hsiao YH, Li SY, Wang SJ, Yang AC, Chen TJ, Perng DW (2013) The effect of cold temperature on increased exacerbation of chronic obstructive pulmonary disease: a nationwide study. PLoS One 8:e57066. https://doi.org/10.1371/ journal.pone.0057066

Vold ML, Aasebø U, Hjalmarsen A, Melbye H (2012) Predictors of oxygen saturation $\leq 95 \%$ in a cross-sectional population based survey. Respir Med 106:1551-1558. https://doi.org/10.1016/j.rmed. 2012.06.016

Publisher's note Springer Nature remains neutral with regard to jurisdictional claims in published maps and institutional affiliations. 